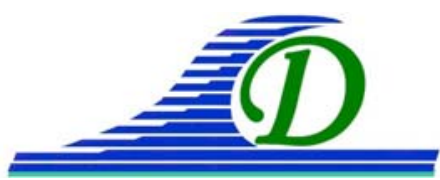

XIII ${ }^{\text {ìmes }}$ Journées Nationales Génie Côtier - Génie Civil Dunkerque, 2-4 juillet 2014

DOI:10.5150/jngcgc.2014.064 @ Editions Paralia CFL

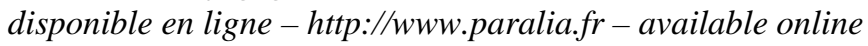

\title{
A new high frequency remote sensing based method: application to the swash zone of a very high reflective beach under high energetic conditions (Grand Popo, Benin)
}

\author{
Raimundo IBACETA ${ }^{1,2}$, Rafael ALMAR ${ }^{2}$, Jean-Pierre LEFEBVRE ${ }^{2}$, \\ Trinity MENSAH-SENOO ${ }^{3}$, Wahab LARYEA ${ }^{3}$, Bruno CASTELLE ${ }^{4}$,

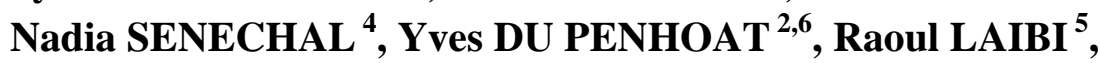 \\ Norbert HOUNKONNOU ${ }^{6}$
}

1. Universidad Técnica Federico Santa María, Departamento de Obras Civiles Valparaiso, Chile.raimundo.ibaceta@alumnos.usm.cl

2. UMR LEGOS (CNRS-IRD-CNES- Université de Toulouse III)

Toulouse, France.rafael.almar@ird.fr,jean-pierre.lefebvre@ird.fr

3. University of Ghana, Departament of Marine and Fisheries Sciences

Accra, Ghana.tri_box3@hotmail.com,sowah_laryea@yahoo.com

4. EPOC, Université de Bordeaux/CNRS

Talence, France.

b.castelle@epoc.u-bordeaux1.fr,n.senechal@epoc.u-bordeaux1.fr

5. Université Abomey Calavi, Departement des Sciences de la Terre

Cotonou, Republic of Benin.

raoulaibi@yahoo.fr

6. ICMPA-UNESCO

Chair, International Chair in Mathematical Physics and Applications

Cotonou, Republic of Benin.

norbert.hounkonnou@cipma.uac.bj ; yves.dupenhoat@cipma.net

\begin{abstract}
:
A new remote sensing method based on video imaging is tested on a steep reflective beach (Grand Popo, Benin) to characterize the variation of the bed level and water level in the swash. The set up used enables the measurement of the wave by wave impact of swash on the beach morphology. Large variations up to $10 \mathrm{~cm}$ of the bed level are observed at periods longer than group periods, suggesting a substantial morphological control on the swash dynamics. The effect of individual swash events on high frequency change of bed level is taken into account relating hydrodynamics and morphodynamics variables to the bed evolution. Preliminary results show a strong correlation of the high frequency bed change with swash hydrodynamics and group influence.
\end{abstract}

Keywords:

Nearshore, Swash, Sediment transport, Beach Cusp, Video, Remote sensing, Pixel intensity, Individual swash, Swash interaction, Benin. 


\section{Introduction}

The swash zone is a highly dynamic zone of the nearshore experiencing large levels of sediment transport, turbulence and large rates of morphological changes in the short term (swash to swash events) to long term (tidal cycle, days). In particular, the processes associated to the energy transfer between short and long waves and beach reflection remains a research challenge, but the last is crucial to understand how the swash zone affects the long wave behavior, the standing wave patterns and the interaction with the morphology (MASSELINK \& PULEO, 2006). For example, recent studies using laboratory and numerical data (ALMAR et al., 2012) have shown the major control of swash slope on the outgoing reflected wave as well as on the standing long wave pattern, being the swash a low frequency filter in which the flatter the beach the lower frequency of the outgoing component. Moreover, the impact of individual swash events is still poorly addressed. In fact, recent observations have shown complexity of individual swash impact event on erosion/accretion and suggested the role played by the interaction between the uprush and backwash on net sediment transport as well as the swash interaction of individual events due to swash saturation (BLENKINSOPP et al., 2010). Regardless the importance of this zone, the wave transformation on this area is insufficiently understood due to lack of field data.

For a sequence of waves approaching the beach, the degree of swash interactions depends on the ratio between the natural period of individual swash events Ts and the incident wave period T (BROCCHINI \& BALDOCK, 2008). For $\mathrm{T}>\mathrm{Ts}$ little or no interaction occurs, where swash interaction occur between incident waves and the uprush or backwash of preceding waves for Ts $>\mathrm{T}$. This interaction may generate a range of scales of new motion such as hydraulic jumps, low frequency waves, turbulence and a high degree of energy dissipation.

A new method based on remote sensing video imaging processing was developed to measure swash zone variations from short scales (swash to swash event) to a longer scale (hours). This paper considers the following specific objectives:

a) Describe different types of individual swash events: This is conducted by studying the wave transformation along the cross-shore direction including 2D interactions related to non-uniform alongshore beach morphology.

b) Variation of bed evolution: Finding the mechanisms behind the change in bed evolution in the short scale (swash event) and relate it to the long/macro scale evolution.

\section{Study Site, Instruments and Measurements}

A field study was conducted in 2013 at the Grand Popo beach $\left(6.2^{\circ} \mathrm{N}, 1.7^{\circ} \mathrm{E}\right)$ in Benin, Gulf of Guinea. The selected site is representative of the beaches of the bight of Benin Coast, presenting an open wavedominated (ECMWF 1957-2013 annual wave averages $\mathrm{Hs}=1.36 \mathrm{~m}, \mathrm{Tp}=9.4 \mathrm{~s}$, Dir=S-SW ) and microtidal environment (from $0.3 \mathrm{~m}$ to $1.8 \mathrm{~m}$ for 


\section{XIII ${ }^{\text {èmes }}$ Journées Nationales Génie Côtier - Génie Civil \\ Dunkerque, 2-4 juillet 2014}

neap and spring tidal ranges respectively) exposed to long swells generated at high latitudes in the South Atlantic with an oblique incidence of $15^{\circ}$ to $20^{\circ}$. The beach presents an alongshore uniform low-tide terrace and a steep high tide reflective part ( $\beta=0.16$, figure $1 \mathrm{~b})$ characterized by a double beach cusp system $(\mathrm{L} \sim 30 \mathrm{~m})$ measured by topographic surveys.

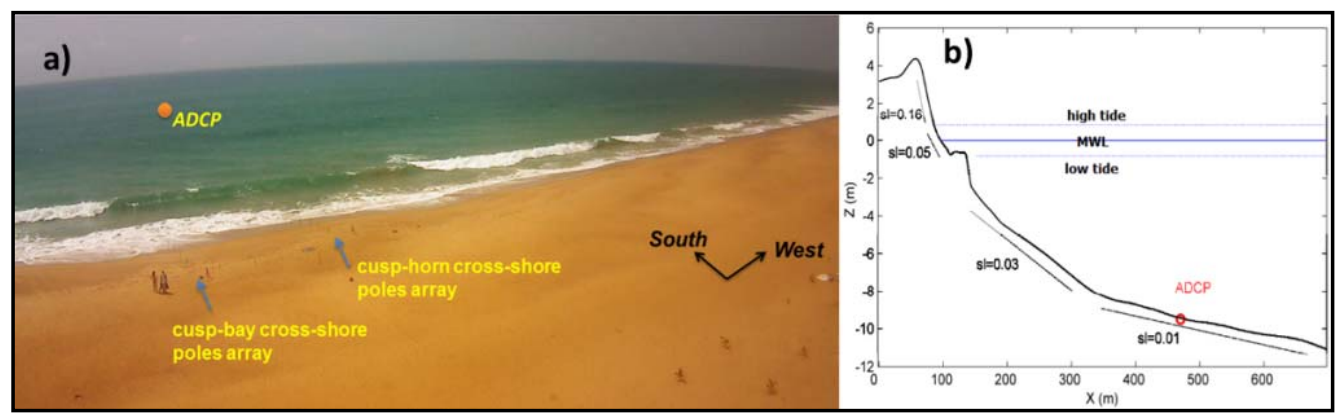

Figure 1. a) Representation of the study site. b)alongshore averaged beach profile.

Incident waves were measured using an acoustic Doppler current profiler (ADCP) moored offshore at 8 (m) depth (ALMAR et al., 2014). The experimental setting consisted of 2 cross-shore transects of black-painted wooden poles (figure 1a and 2a), one on a bay cusp and the other on the corresponding cusp horn. Each transect had up to 7 poles positioned every $5(\mathrm{~m})$ approximately. For each transect, a high definition video camera was used to monitor the swash elevation and bed elevation with an acquisition rate of $25 \mathrm{~Hz}$ during 5 days (from 22 to 26 Feb.2013) for almost a complete tidal cycle for each day. A validation of this method can be found in IBACETA et al. (2014).

\section{Data processing}

Generation of time stacks for each video pole relies on the optical difference between the black poles and the water and bed level (white to yellowish color). The method itself consists in stacking into a secondary image, pixels extracted along a line passing along each pole from every video frame. The location of the poles is automatically achieved from difference in pixel intensity (blue points on figure $2 \mathrm{~b}$ ). In order to circumvent the possible movement of the poles due to wave impact, the extraction line is corrected so that it passes through the origin blue point and covers the maximum of black pixels (yellow dashed lines on figure 2b). These corrections are performed at frequency 25/3 $\mathrm{Hz}$ for every pole. Finally, a quasi-cross-shore line is used to qualitatively asses the variation of the swash run up and run down (figure 2b). The detection of the bed and water interface relies on the abrupt change in pixel intensity. Time stacks were converted into binary matrix by comparing the pixel intensities to an estimated threshold representative of water or bed, and pole transition (figure 3b and 3c). 


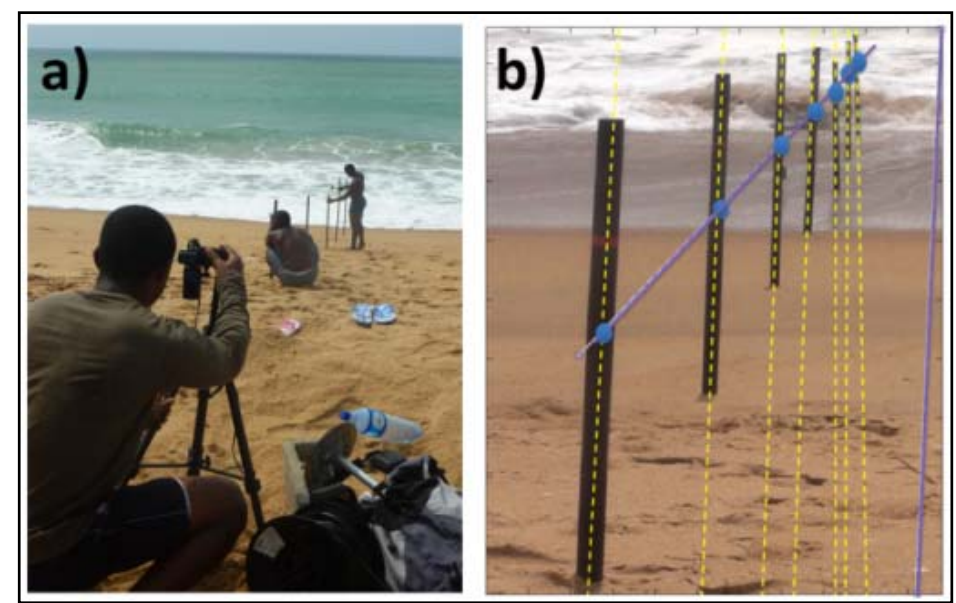

Figure 2. a) Transect video camera representation. b)Camera Overview. Purple lines represent the stack line to detect the poles position and a quasi cross-shore stack.

Finally, boundaries in binary converted time stacks were determined. Small differences between detected bed and real bed level were corrected manually when necessary. A final representation of 3 swash events time stack and its detection is shown in figure 3d. The transformation from pixel coordinates to real world coordinates was done considering the thickness in pixels of a red adhesive tape of known width, near the top of each pole.

\section{Results}

\subsection{Description of swash events}

The description of some typical swash events observed during the field study is explained here with reference to the figures $4 \mathrm{a}$ and $4 \mathrm{~b}$. Three characteristic times in a swash event can be deducted from a time stack; the time when the uprush reaches a given pole, the time corresponding to the maximum reach of the swash (run up) and the end of a swash event for the corresponding pole. These times are indicated on figure 3a as ta,tb and tc, respectively.

Free swash event (figure 4, 13:20:54- 13:21:05): These types of events are characterized by a regular shape with an initial bore travelling shoreward, conserving its shape up to the point of maximum extension as its height and velocity decrease. After the uprush stops, the flow reverses to seaward direction due to gravity (backwash) without being influenced by the next incident wave.

Swash to Swash Interactions (figure 4, 13:20:32- 13:20:45): Interaction between a backwash and the next uprush can happen when Ts $>\mathrm{T}$. This interaction tends to hinder the uprush extension concentrating high levels of turbulence over a narrow area. As the hindering by the backwash ceases, the uprush propagates shoreward but along a reduced 


\section{XIII ${ }^{\text {èmes }}$ Journées Nationales Génie Côtier - Génie Civil \\ Dunkerque, 2-4 juillet 2014}

extension since energy has been dissipated during the hindering. This mechanism was observed several times during the field experiment.

Two dimensional interaction (figure 4, 13:22:08-13:22:13): It was common to see interactions coming from the beach cusp-horn as an alongshore flow. This is observed on the elevation time series as quasi uniform shape events because of the alongshore local slope nearly constant on the direction of this secondary interaction.

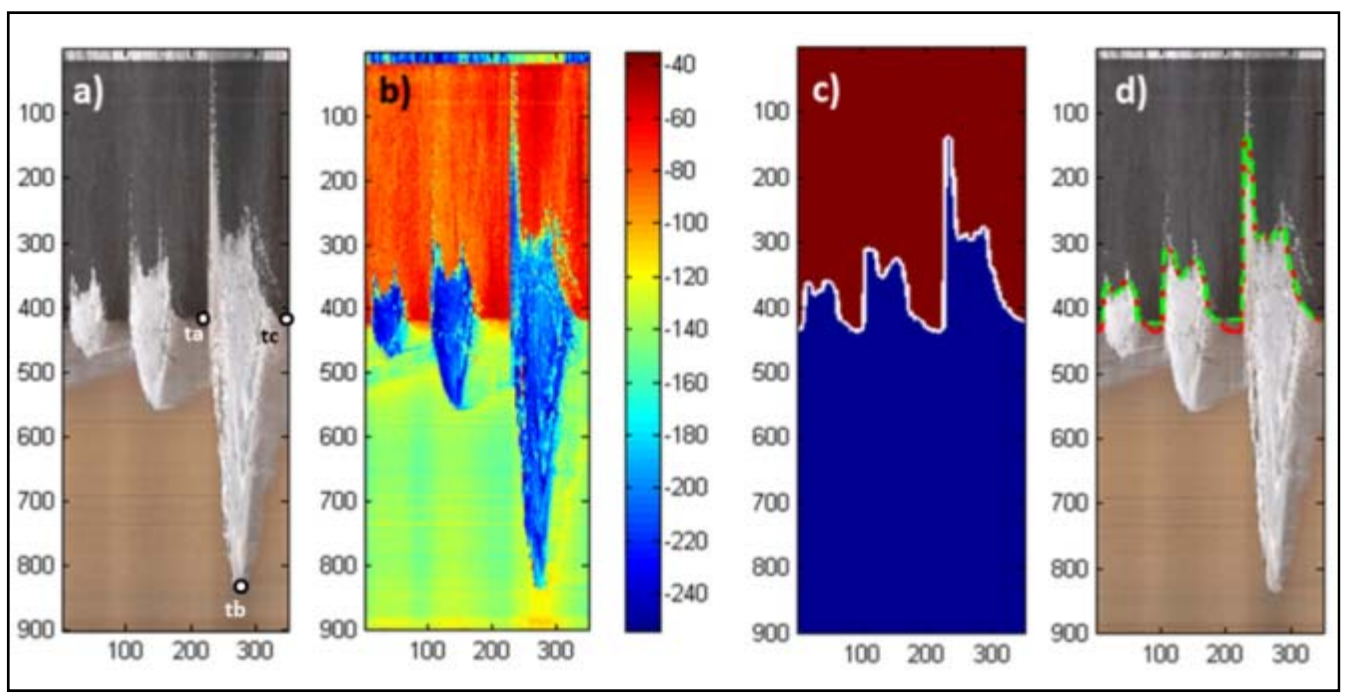

Figure 3. a) 3 swash event original Timestack b) Pixel intensity c) Binary values and its contour d) Timestack with (red) detected contour and (green dashed) corrected contour.

\subsection{Bed evolution}

Link between individual swash event and day scale: Preliminary results show the bed evolution along a cross-shore transect, with a global net pattern of erosion or accretion being the result of the sum of accretion and erosion events in the very short scale (swash event). Figure 5a shows the evolution of the bed level during 6 hours for pole 7 (the most shoreward) to pole 11 (the most seaward). Shoreward poles experienced net erosion whereas the seaward poles experienced a net accretion pattern, resulting in a decrease of the mean beach slope. This global behavior was consistent with topographic surveys conducted during low tide with GPS (see SENECHAL et al., 2014).

Individual swash impact: Individual swash events for a pole were detected automatically by searching times ta, tb and tc of certain swash events. In order to study the effect of individual events on bed evolution, different variables were calculated for each event $i$ with the aim of finding how the last ones contribute on the variation of bed evolution $\Delta z$. The variables used were the swash celerity $c$ calculated as the ratio of the distance between two consecutive poles and the time gap corresponding to the passing of an event at two consecutive poles, the event shape asymmetry defined as $t c-t b / t b-t a$, the maximum height $h$ of the corresponding event, an interaction 
parameter I defined as $t a_{i}-t c_{i-1}$ and the change in bed evolution height $\Delta z_{i-1}, \Delta z_{i-2}, \Delta z_{i-3}$, of the previous 3 swash events for the same pole. The last three parameters were chosen in order to consider possible group influence on the morphological variation of the beach. Asymmetry was included as an approach of the differences in sediment transport on the up rush and backwash phases due to different behavior on sediment movement since sediments tend to settle on the backwash flow because of the lower flow velocity (BROCCHINI \& BALDOCK, 2008).

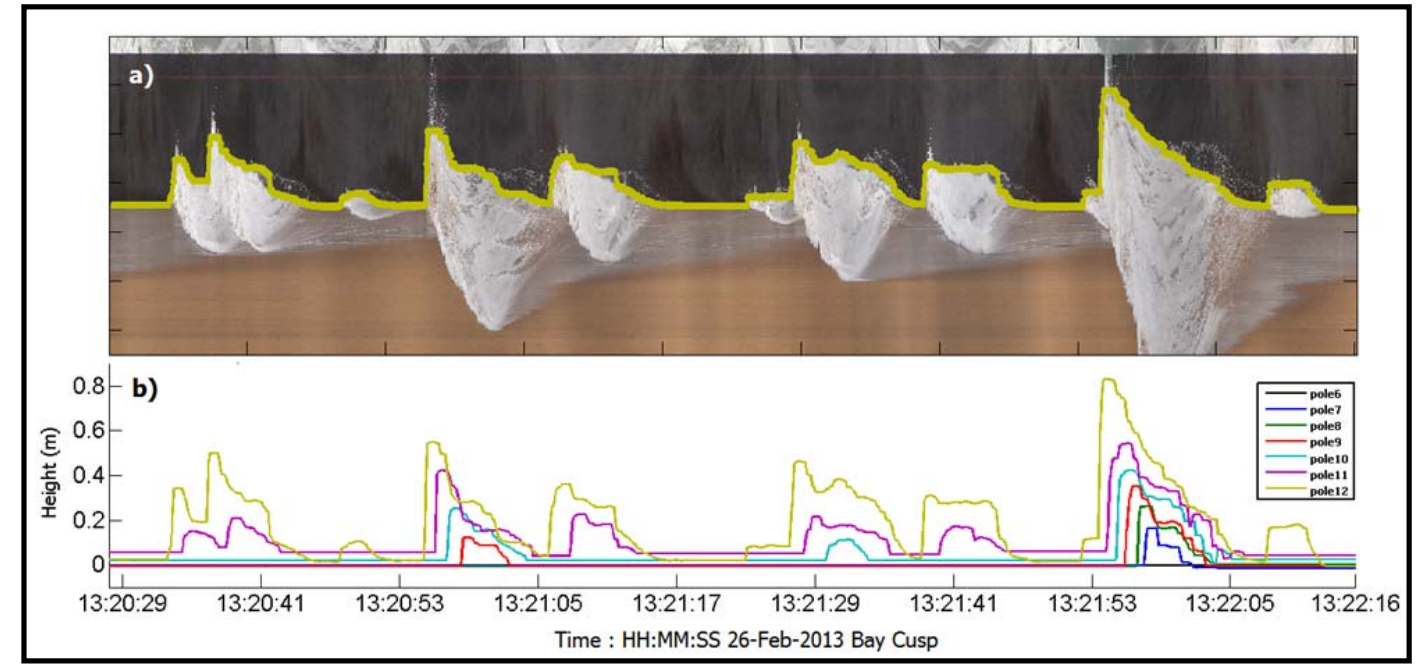

Figure 4. a) Events on the seaward pole and their timestack. b) Cross-shore variation along the bay cusp transect of the events.

Preliminary studies were conducted over 668 consequent events at pole 10 (figure 5b). Further, due to high amount of zero values of $\Delta z_{i, i=1,2, \ldots, 668}$, of, only 83 extreme events of erosion and accretion $\left(\operatorname{abs}\left(\Delta z_{i}\right)>1.5 \operatorname{std}\left(\Delta z_{i}\right)\right.$ ) were chosen with the scope of reconstruct these values as a multiple linear regression of the type $\Delta z_{i}=\Sigma_{\mathrm{i}} a_{i} x_{i}$, being $x_{i}$ the hydro and morphodynamics variables explained above and their respective $a_{i}$ regression coefficients. The relative influence of above described parameters to the variation in bed evolution in the short scale is shown as percentages in table 1. Magnitudes of the percentages indicate a substantial group influence on the morphological variation.

Celerity contributes as expected by the classical theory of sediment transport. On the other hand, greatest height of each event contributes less since this height did not occur always on the initial bore height $H_{b}$ (as that could be related with the bore celerity, $\left.\propto\left(g H_{b}\right)^{1 / 2}\right)$. On the same way, the interaction and asymmetry variables do not contribute as much as to be a key factor. Finally, with this linear model it was possible to reconstruct the $67 \%$ of the variation of the measured values of $\Delta z$. This value was calculated as the ratio of the standard deviation of the reconstructed values $\Sigma_{\mathrm{i}} a_{i} x_{i}$ to the standard deviation of the measured values of $\Delta z_{i}$. 


\section{XIII ${ }^{\text {èmes }}$ Journées Nationales Génie Côtier - Génie Civil \\ Dunkerque, 2-4 juillet 2014}
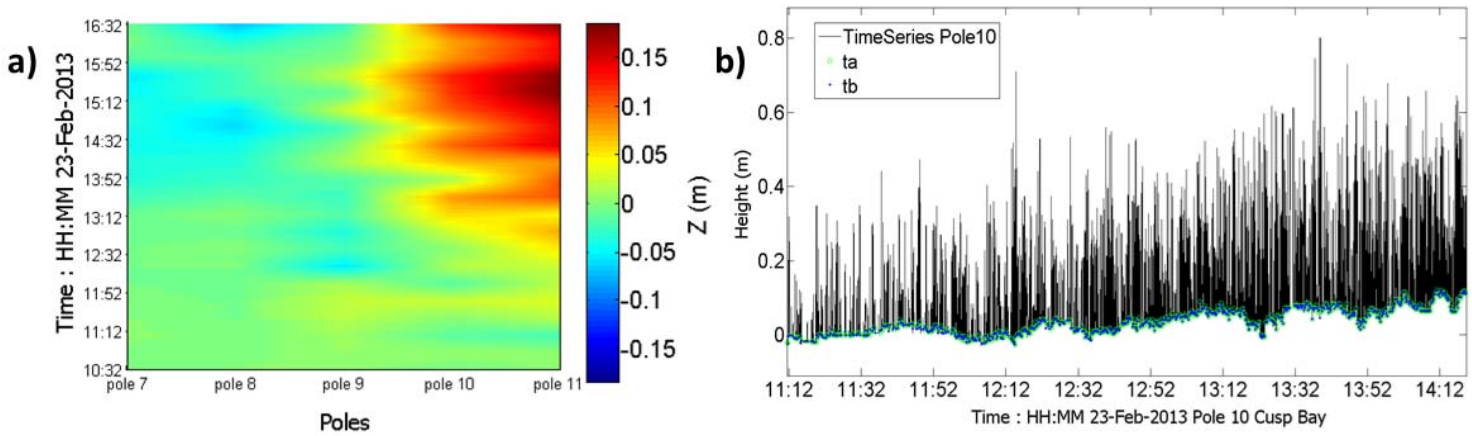

Figure 5. a) Variation of the bed level along the cross shore transect b) Swash events considered for the regression analysis. Blue and green points are the detected initial and end times of each event. These points also define the bed evolution.

Table 1. Contribution of each variable to the change in bed level.

\begin{tabular}{ll}
\hline Variable & Percentage (\%) \\
\hline Asymmetry & 6.63 \\
Celerity & 11.19 \\
Height & 2.00 \\
Interaction & 7.97 \\
$\Delta z_{i-1}$ & 46.26 \\
$\Delta z_{i-2}$ & 11.01 \\
$\Delta z_{i-3}$ & 14.89 \\
Total & $\mathbf{1 0 0}$ \\
\hline
\end{tabular}

\section{Conclusions}

A enabled a satisfying description of wave transformation on the cross-shore direction as well as the high frequency variation on the bed evolution which in turn allowed the description of the long/macro scale evolution. Future research should consider the possibility of comparing net change due to high frequency with long/macro scale surveys measured at same times/locations. Bed level variation on the short scale was reconstructed using hydrodynamics and morphodynamics variables, achieving a $67 \%$ of the variation. This reconstruction was achieved using a linear model which in turn could be improved using a nonlinear representation or a combination of both. The effect of precedent events changes in bed evolution were the most important in terms of contribution to this variation, suggesting a wave group influence that should be further investigated. Celerity also showed up to be important, as classical sediment transport theory suggests. Future research on this area focused on wave by wave transformation and short scale bed level changing should incorporate the effect of more possible variables affecting the hydrodynamics and morphodynamics on the swash zone. Variables such as water saturation on the swash zone, infragravity waves and the energy transfer from the high to the low frequency, standing waves patterns (see ALMAR et al., 2012), and so on, should be taken into account. Moreover, variation of bed 
evolution model could be better represented taking into account its variation along the cross-shore extension using as more poles as possible. Finally, method's accuracy has still to be studied, as a second field study at Grand Popo will include measurements using hourly bed GPS measurements and pressure sensors.

\section{Acknowledgement}

The Field study was funded by the INSU LEFE and EC2CO programs, the IRD and the UNESCO co-chair CIPMA. RI thanks CNRS' grant to do an internship at LEGOS and R. Almar and P. Catalan (USM) for their continuous support during the internship.

\section{References}

ALMAR R., ALMAR R., CIENFUEGOS R., GONZALEZ E., CATALAN P., MICHALLET H., BONNETON P., CASTELLE B., SUAREZ L. (2012). Barred-beach morphological control on infragravity motion. Proceedings of the International Conference on Coastal Engineering 2012, Santander, Spain.

ALMAR R., HOUNKONNOU N., ANTHONY J., CASTELLE B., SENECHAL N., LAIBI R., MENSAH-SENOO T., DEGBE G., QUENUM M., DOREL M., CHUCLA R., LEFEBVRE J., DU PENHOAT Y., LARYEA W., ZODEHOUGAN G., SOHOU Z., ADDO K., IBACETA R., KESTENARE E. (2014). The Grand Popo 2013 beach experiment, Benin, West Africa: from short timescale processes to their integrated impact over long-term coastal evolution. Proceedings of the International Coastal Symposium 2014, Durban, South Africa.

BLENKINSOPP C.E., TURNER I.L., MASSELINK G., RUSSEL P.E. (2010). Swash zone sediment fluxes: Field observation. Coastal engineering, Vol. 58(1), pp 28-44. http://dx.doi.org/10.1016/j.coastaleng.2010.08.002

BROCCHINI M., BLDOCK T. (2008). Recent advances in modeling swash zone dynamics: Influences of surf-swash interaction on nearshore hydrodynamics and morophodynamics. Reviews of Geophysics, Vol. 46, No. 3, RG3003. http://dx.doi.org/10.1029/2006RG000215

IBACETA R. et al. (2014). Estudio comparativo de la dinámica de swash altamente energético en una playa disipativa (Mataquito, Chile) y reflectiva (Grand Popo, Benin). Proceed. of the XII Latin-American Congress of Hydraulic Eng. 2014, Santiago de Chile, Chile.

MASSELINK G., PULEO J. (2006). Swash-zone morphodynamics. Continental Shelf Research, Vol. 26, pp.661-680. http://dx.doi.org/10.1016/j.csr.2006.01.015

SENECHAL N., LAIBI R., ALMAR R., CASTELLE B., BIAUSQUE M., LEFEBVRE J., ANTHONY J., DOREL M., CHUCLA R., HOUNKONNOU N., DU PENHOAT Y. (2014). Observed destruction of a beach cusp system in presence of a doublecoupled cusp system: the example of Grand Popo, Benin. Proceedings of the International Coastal Symposium 2014, Durban, South Africa. 